\title{
Exuberant mucosal granulation by a self- expanding metal stent leading to complete closure of esophageal perforation
}

A 65-year-old man was hospitalized for massive hematemesis due to esophageal varices secondary to liver cirrhosis. Urgent upper endoscopy revealed esophageal varices, which were spurting blood, in the mid esophagus ( $\bullet$ Fig. 1). An endoscopic injection sclerotherapy (EIS) was carried out, using $5 \%$ ethanol-amine oleate under X-ray guidance. The patient underwent three sessions of EIS, at weekly intervals. On the 6th day after the final session, the patient complained of anterior chest pain and a high fever. A chest $\mathrm{X}$-ray examination revealed a right pleural effusion ( $\bullet$ Fig. 2). Urgent upper endoscopy revealed an esophageal perforation directly into the right pleural space (ब Fig. 3). No perforation into the mediastinum was observed.

Although percutaneous drainage of the pleural space was carried out continuously for 37 days, the fistula did not close. An attempt was then made to close this perforation with hemoclips, but it proved to be unsuccessful because of mucosal fibrosis after the EIS. Moreover, surgery was not indicated because the clinical stage of liver cirrhosis was Child grade B. On the basis of previous reports [1-3], a self-expanding metal stent (SEMS) was selected to seal the esophageal perforation ( Fig. 4). At 25 days after the stent placement, massive mucosal granulation was observed to have dramatically occurred from the mid esophagus around the fistula, and the perforation had therefore completely closed ( $\bullet$ Fig. 5). The SEMS had also passed into the patient's stomach by this time ( $\bullet$ Fig. 6). It was safely removed with the assistance of an overtube.

These results suggest that the moderate pressure from the SEMS and the appropriate oral nutrition intake might have induced a synergistic effect to promote the development of massive mucosal granulation around the fistula. In conclusion, the application of a SEMS may therefore be an effective treatment modality to close benign esophageal perforations without stricture.

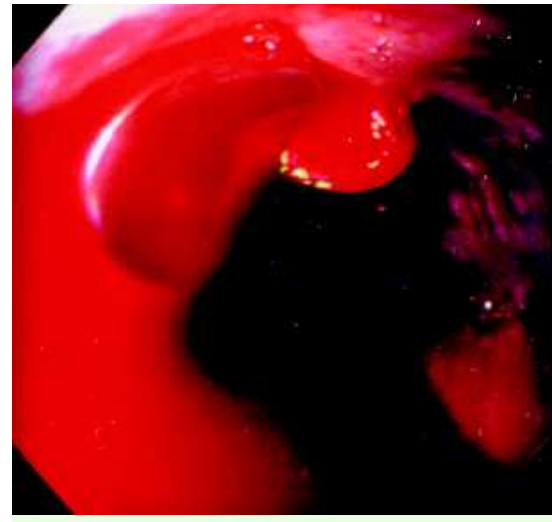

Fig. 1 Endoscopic view of spurting bleeding from esophageal varices in the mid esophagus.

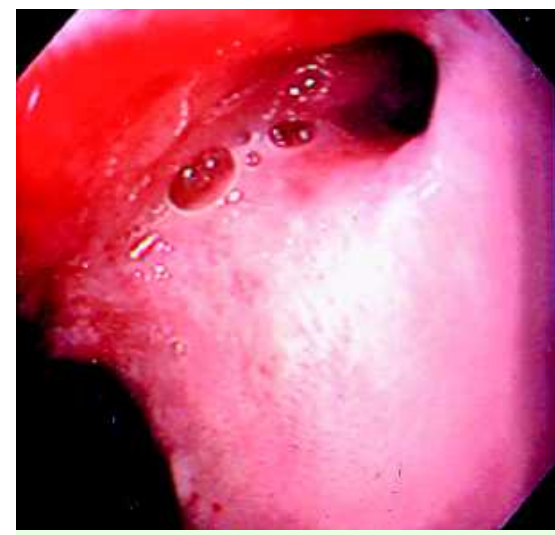

Fig. 3 The esophageal perforation into the right pleural space.

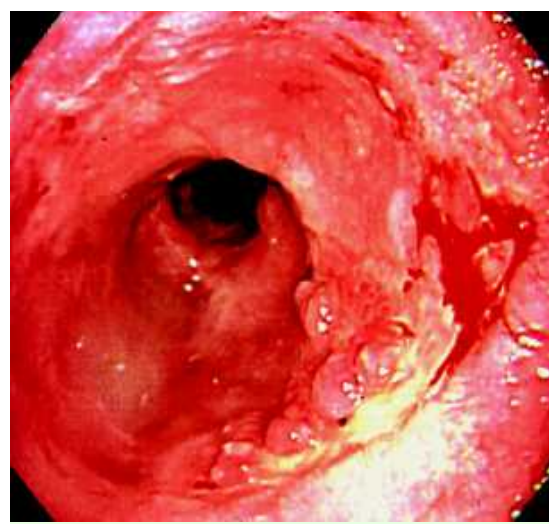

Fig. 5 Healthy exuberant mucosal granulation tissue at the previous fistula site.

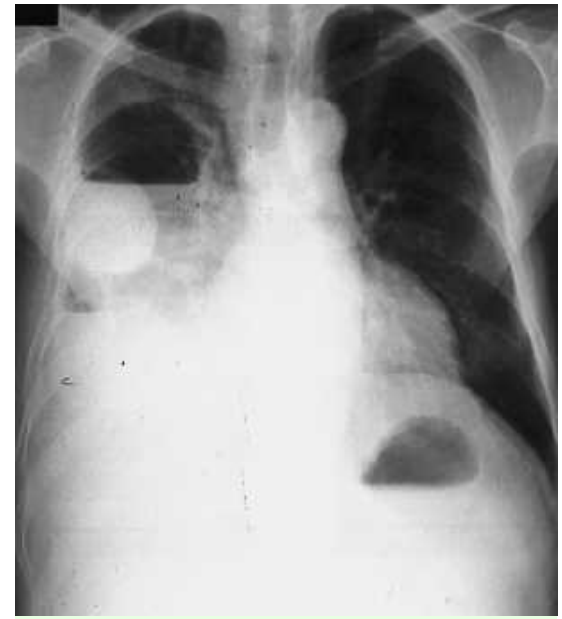

Fig. 2 Chest X-ray showed a pleural effusion in the right pleural space.

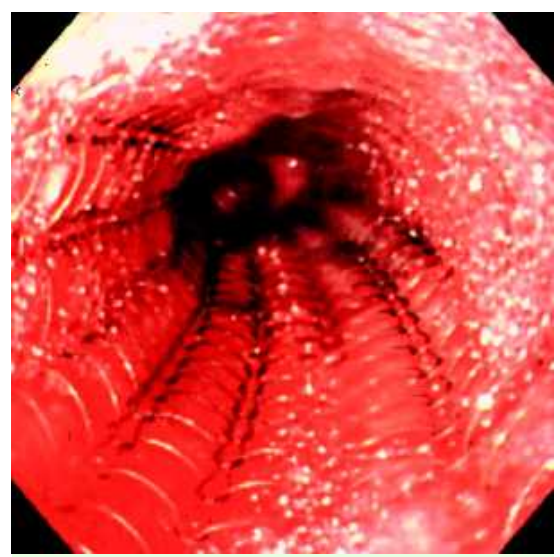

Fig. 4 A self-expanding metal stent (SEMS) was positioned and deployed in the mid esophagus.

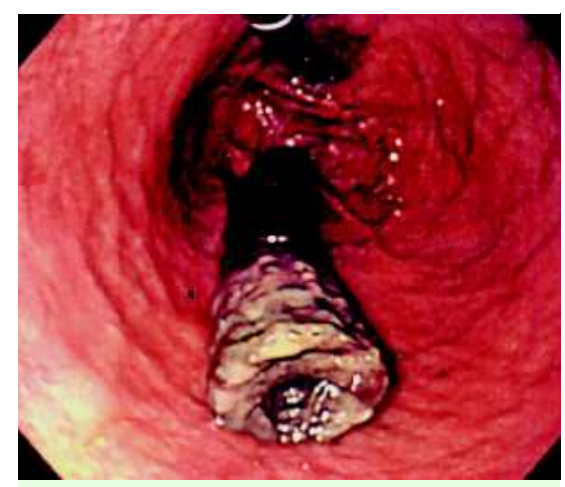

Fig. 6 The SEMS passed naturally into the stomach and was removed using an overtube. 
Endoscopy_UCTN_Code_TTT_1AO_2AD

Endoscopy_UCTN_Code_TTT_1AO_2AZ

\section{S. Yoshida ${ }^{1}$, M. Shimada', T. Ueno ${ }^{2}$,}

M. Yoshino

1 Department of Gastroenterology, Internal Medicine, TMG Asakadai Central General Hospital, Saitama, Japan

${ }^{2}$ Critical Care Medicine, Hachioji Medical Center, Tokyo Medical University, Tokyo, Japan

\section{References}

1 Johnsson E, Lundell L, Liedman B. Sealing of esophageal perforation or ruptures with expandable metallic stents: a prospective controlled study on treatment efficacy and limitations. Dis Esophagus 2005; 18: 262 266

2 Siersema PD, Homs MY, Haringsma J et al. Use of large-diameter metallic stents to seal traumatic nonmalignant perforations of the esophagus. Gastrointest Endosc 2003; 58: 356-361

3 Fiorini A, Fleischer D, Valero J et al. Self-expandable metal coil stents in the treatment of benign esophageal strictures refractory to conventional therapy: a case series. Gastrointest Endosc 2000; 52: 259-262
Bibliography

DOI $10.1055 / \mathrm{s}-2008-1077526$

Endoscopy 2008; 40: E244-E245

(c) Georg Thieme Verlag KG Stuttgart · New York . ISSN 0013-726X

Corresponding author

\section{S. Yoshida, MD, PhD}

Department of Gastroenterology,

Internal Medicine

TMG Asakadai Central General Hospital

1-8-10, Nishi-benzai, Asaka-shi

Saitama 351-8551

Japan

Fax: + 81-48-4662735

carcinogenesis@hotmail.com 